\title{
Symptomatic Reinfection in Previously Recovered Coronavirus Disease 2019 (COVID-19) Geriatric Patient
}

\author{
Dhigishaba Jadeja $^{1}$, Payel Basak ${ }^{2}$ \\ 1. Graduate Medical Education, Gujarat Adani Institute of Medical Sciences, Bhuj, IND 2. Graduate Medical Education, \\ College of Medicine and Jawaharlal Nehru Memorial (JNM) Hospital, Kalyani, IND
}

Corresponding author: Dhigishaba Jadeja, dhigishabajadeja@gmail.com

\begin{abstract}
Can a patient diagnosed with coronavirus disease 2019 (COVID-19) be infected again? This issue appears to be unsolved. Protective immunity following infection with COVID-19 is still not fully known. In the coming months, an awareness of COVID-19 reinfection will be crucial in directing government and public health policy managements. Here, we present a case of symptomatic reinfection following recovery from COVID-19 in a geriatric patient.
\end{abstract}

Categories: Internal Medicine, Infectious Disease

Keywords: coronavirus disease, reactivation

\section{Introduction}

As of February 23, 2021, the novel causative virus, the severe acute respiratory syndrome coronavirus 2 (SARS-CoV-2), has affected 11,030,176 people and caused 156,567 deaths, with a case fatality rate (CFR) of 1.41 percentage (\%) in India, which was $1.60 \%$ on September 22, 2020 [1]. Gao et al. reported the prevalence of recurrent SARS-CoV-2 $17 \%$ in previously infected COVID-19 patients [2]. The pandemic is becoming more complicated, and disease prevention, both in terms of morbidity and mortality rates, is becoming more difficult. In addition to the two negative real-time reverse-transcription polymerase chain reaction (RT-PCR) tests for SARS-CoV-2 drawn at least 24 hours apart, the patients infected with coronavirus disease 2019 (COVID-19) may easily discontinue home isolation and are deemed non-infectious after complete symptomatic recovery. Current literature is buzzing with the symptomatic reinfection in patients who previously recovered from COVID-19 [3]. Risk factors for the reactivation of SARS-CoV-2 might be associated with the type of immunosuppressive treatment, host factors such as the elderly, ethnicity, underlying diseases such as diabetes, cancer, obesity, cardiac disease, virological factors, weak immune response due to non-invasive infection, inadequate monitoring of SARS-CoV-2 infection, an inflammatory reaction that has resurfaced as a consequence of an inappropriate immune response, and different viral strains $[4,5]$. While infection with the SARS-CoV-2 results in a visible immune response, it is unclear if previously infected individuals are susceptible to reinfection with SARS-CoV-2. Infection with SARS-CoV-2 causes the development of neutralizing antibodies in patients [6]. However, the extent to which this immune response suggests defensive immunity against subsequent SARS-CoV-2 infection is yet to be

Review began 03/09/2021 Review ended 03/16/2021 Published 03/17/2021

\section{() Copyright 2021}

Jadeja et al. This is an open access article distributed under the terms of the Creative Commons Attribution License CC-BY 4.0., which permits unrestricted use, distribution, and reproduction in any medium, provided the original author and source are credited.

\section{Case Presentation}

A 79-year-old male presented in the emergency room with cough, breathlessness, and fever $\left(38.5^{\circ} \mathrm{C}\right)$. The patient's past medical history was remarkable for chronic ischemic heart disease and smoking.

The patient's recent clinical history had begun on July 9, 2020 with the appearance of a fever $\left(27.9^{\circ} \mathrm{C}\right)$, dry cough, breathlessness. On the 14th day of illness, with the emergence of dyspnea, there was a deterioration of clinical symptoms and so the patient was hospitalized in the COVID care center. There, he tested positive for SARS-CoV-2 by RT-PCR from a nasopharyngeal swab, and his chest computed tomography (CT) scan revealed bilateral infiltrates. During the hospital course, he was treated with favipiravir 1600 milligram (mg) twice daily followed by $600 \mathrm{mg}$ twice daily for seven days and hydroxychloroquine $400 \mathrm{mg}$ twice daily on first day followed by $200 \mathrm{mg}$ twice daily for another four days, together with supportive oxygen with the nasal cannula at flow 1.5 liters/minute $(\mathrm{L} / \mathrm{m})$.

By the 18th day of illness, respiratory symptoms had resolved. Laboratory biomarkers were negative including C-reactive protein (CRP), positive immunoglobulin G (IgG) antibody, and negative immunoglobulin M (IgM) antibody for COVID-19, and nasopharyngeal swabs for SARS-CoV-2 were taken serially two times, resulting in negative RT-PCR. The patient was deemed at home to be healed and discharged.

On August 17, 2020, he again developed symptoms in the form of intermittent $38^{\circ} \mathrm{C}$ fever, generalized body 


\section{Cureus}

ache, throat pain, and his rapid antigen test (RAT) returned positive. On August 19, 2020, the patient needed rehospitalization where his COVID-19 RT-PCR returned positive with a cycle threshold (CT) score of 17 indicative of high viral load, confirming a case of COVID-19 reinfection (Figure 1).

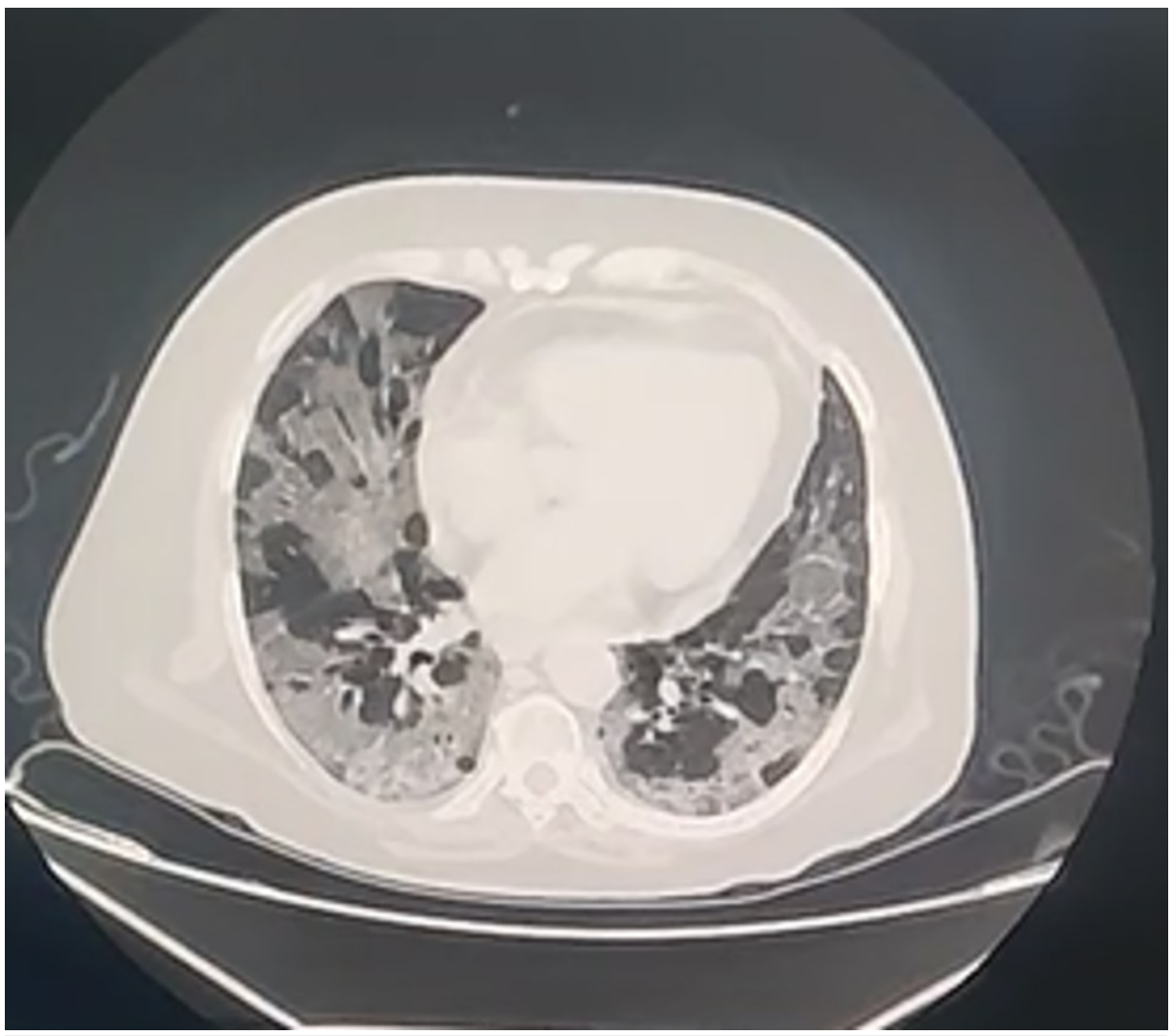

FIGURE 1: Computed tomography (CT) findings in recovered COVID-19 patient

His inflammatory profile revealed CRP of $52.8 \mathrm{mg} / \mathrm{L}$ and IL-6 of 20.4 picograms per milliliter (pg/mL). After discussion with the COVID care team, the patient was treated symptomatically. After eight days, the patient became afebrile and no respiratory symptoms observed since then.

\section{Discussion}

SARS-CoV- 2 is characterized by hyper-cytokinemia, which typically occurs in the second week of COVID-19 and is associated with immunodeficiency as well as hyper inflammation, the latter manifesting as a cytokine storm [7]. COVID-19 was earlier thought to be a respiratory disease, but it has affected multiple organs [811]. A study done by Desai et al. reported that COVID-19 has caused not only physical distress but also had a negative impact on social, economic, and psychological well-being [12]. At present, literature is buzzing with the symptomatic reinfection of SARS-CoV-2 in recovered COVID-19 patients. Previous exposure to SARS-CoV-2 does not necessarily result in total immunity being guaranteed. A study done by Tillett et al. on genomic analysis of SARS-CoV-2 revealed genetically significant variations between each variant associated with each infection case. Furthermore, they also reported that the second infection was clinically more severe than the first and severity might be associated with the viral load, the virulence of the viral strain [13]. A study done by Song et al. has reported that the post-negative positive RT-PCR findings may be due to the identification of ribonucleic acid (RNA) particles rather than reinfection in individuals that have recovered from COVID-19 [14]. Studies have shown that the humoral response can be poor in patients who are asymptomatic at the time of the post-negative positive RT-PCR test and may improve progressively. In all COVID-19 patients, however, IgM and IgG become detectable between the third and fourth weeks of the onset of their clinical disease [6,15]. In our case, IgG antibody was found to be positive while IgM antibody was negative for COVID-19. The confirmation of re-infection has several important implications. First, herd immunity is unlikely to eradicate SARS-CoV-2, although it might make future infections milder than the first infection. Second, the probability of COVID-19 reinfection indicates that, as with other human coronaviruses, COVID-19 could become widespread in some pockets of seasonal outbreaks. Third, vaccinations may not be sufficient to offer a lifetime defense against COVID-19, and even though we create a vaccine, sustainable immuno-protection may require booster dosing. Fourth, vaccine studies may have to be performed in such patients who have recovered from COVID-19 [16]. A vaccination that stimulates cross- 
protective immunity will be an effective tool for preventing or reducing the severity of disease caused by potential pandemic coronavirus strains. As a result, even if reinfection happens when antibody levels are low, pre-existing T-cell immunity can deter clinically serious disease [17,18]. SARS-CoV-2 epitopes have been identified in previously circulating human coronaviruses, indicating that they may play a role in the immune defense of COVID-19 unexposed and recovering patients [19]. Furthermore, telemedicine may help to reduce the severity of the infection and prompt identification of recurrence cases in patients with comorbidities [20]. In India and around the world, the lack of systematic genomic sequencing of positive cases restricts the advancements in public health monitoring needed to find these cases. Limitations in SARS-CoV-2 screening and testing worsen the ineffective surveillance attempts being made not only to detect COVID-19 but also to achieve actionable genetic monitoring of this agent.

\section{Conclusions}

This case of reinfection shows that population transmission herd immunity could be an elusive tactic and the production of vaccines needs to be reoriented towards potential single infection weaning immunity. People must take precaution to prevent SARS-CoV-2 infection irrespective of whether they diagnosed previously or not from the public health perspective. Future studies need to focus on immune responses in vitro after reinfection.

\section{Additional Information \\ Disclosures}

Human subjects: Consent was obtained or waived by all participants in this study. Conflicts of interest: In compliance with the ICMJE uniform disclosure form, all authors declare the following: Payment/services info: All authors have declared that no financial support was received from any organization for the submitted work. Financial relationships: All authors have declared that they have no financial relationships at present or within the previous three years with any organizations that might have an interest in the submitted work. Other relationships: All authors have declared that there are no other relationships or activities that could appear to have influenced the submitted work.

\section{References}

1. Ansari AZ, Desai HD, Sharma K, Jadeja D, Patel R, Patel Y, Desai H: Prevalence and cross states comparison of case fatality rate and recovery rate of COVID 19/SARS-COV-2 in India. J Family Med Prim Care. 2021, 10:475-480. 10.4103/jfmpc.jfmpc_1088_20

2. Gao C, Zhu L, Jin CC, Tong YX, Xiao AT, Zhang S: Prevalence and impact factors of recurrent positive SARSCoV-2 detection in 599 hospitalized COVID-19 patients (IN PRESS). Clin Microbiol Infect. 2021, 10.1016/j.cmi.2021.01.028

3. SeyedAlinaghi S, Oliaei S, Kianzad S, et al.: Reinfection risk of novel coronavirus (COVID-19): a systematic review of current evidence. World J Virol. 2020, 9:79-90. 10.5501/wjv.v9.i5.79

4. $\mathrm{Bi}$ J, Ma H, Zhang D, et al.: Does chemotherapy reactivate SARS-CoV-2 in cancer patients recovered from prior COVID-19 infection?. Eur Respir J. 2020, 56:2002672. 10.1183/13993003.02672-2020

5. Gousseff M, Penot P, Gallay L, et al.: Clinical recurrences of COVID-19 symptoms after recovery: viral relapse, reinfection or inflammatory rebound?. J Infect. 2020, 81:816-846. 10.1016/j.jinf.2020.06.073

6. Sethuraman N, Jeremiah SS, Ryo A: Interpreting diagnostic tests for SARS-CoV-2 . JAMA. 2020, 323:22492251. 10.1001/jama.2020.8259

7. Desai HD, Sharma K, Parikh A, et al.: Predictors of mortality amongst tocilizumab administered COVID-19 Asian Indians: a predictive study from a tertiary care centre. Cureus. 2021, 13:13116. 10.7759/cureus.13116

8. Desai HD, Jadeja DM, Sharma K: Takotsubo syndrome a rare entity in patients with COVID-19: an updated review of case-reports and case-series. Int J Cardiol Heart Vasc. 2020, 29:100604. 10.1016/j.ijcha.2020.100604

9. Singhavi R, Sharma K, Desai HD, Patel R, Jadeja DA: A case of hemolytic anemia with acute myocarditis and cardiogenic shock: a rare presentation of COVID-19. Cureus. 2020, 12:e10657. 10.7759/cureus.10657

10. Desai HD, Sharma K, Patoliya JV, Ahadov E, Patel NN: A rare case of varicella-zoster virus reactivation following recovery from COVID-19. Cureus. 2021, 13:e12423. 10.7759/cureus.12423

11. Sharma K, Desai HD, Patoliya JV, Jadeja DM, Gadhiya D: Takotsubo syndrome a rare entity in COVID-19: a systemic review-focus on biomarkers, imaging, treatment, and outcome. SN Compr Clin Med. 2021, 3:62-72. 10.1007/s42399-021-00743-4

12. Desai HD, Sharma K, Jadeja DM, Desai HM, Moliya P: COVID-19 pandemic induced stress cardiomyopathy: a literature review. Int J Cardiol Heart Vasc. 2020, 31:100628. 10.1016/j.ijcha.2020.100628

13. Tillett RL, Sevinsky JR, Hartley PD, et al.: Genomic evidence for reinfection with SARS-CoV-2: a case study . Lancet Infect Dis. 2021, 21:52-58. 10.1016/S1473-3099(20)30764-7

14. Song KH, Kim DM, Lee H, et al.: Dynamics of viral load and anti-SARS-CoV-2 antibodies in patients with positive RT-PCR results after recovery from COVID-19. Korean J Intern Med. 2021, 36:11-14. 10.3904/kjim.2020.325

15. To KK, Tsang OT, Leung WS, et al.: Temporal profiles of viral load in posterior oropharyngeal saliva samples and serum antibody responses during infection by SARS-CoV-2: an observational cohort study. Lancet Infect Dis. 2020, 20:565-574. 10.1016/S1473-3099(20)30196-1

16. To KK, Hung IF, Ip JD, et al.: COVID-19 re-infection by a phylogenetically distinct SARS-coronavirus-2 strain confirmed by whole genome sequencing (IN PRESS). Clin Infect Dis. 2020, 10.1093/cid/ciaa1275

17. Menachery VD, Yount BL Jr, Josset L, et al.: Attenuation and restoration of severe acute respiratory syndrome coronavirus mutant lacking 2'-o-methyltransferase activity. J Virol. 2014, 88:4251-4264. 


\section{Cureus}

10.1128/JVI.03571-13

18. Nainu F, Abidin RS, Bahar MA, et al.: SARS-CoV-2 reinfection and implications for vaccine development . Hum Vaccin Immunother. 2020, 16:3061-3073. 10.1080/21645515.2020.1830683

19. Grifoni A, Weiskopf D, Ramirez SI, et al.: Targets of T cell responses to SARS-CoV-2 coronavirus in humans with COVID-19 disease and unexposed individuals. Cell. 2020, 181:1489-1501.e15.

10.1016/j.cell.2020.05.015

20. Sharma K, Desai HD: Role of self-measured home blood pressure monitoring (HBPM) and effectiveness of telemedicine during the era of COVID-19 pandemic (IN PRESS). SN Compr Clin Med. 2021, 10.1007/s42399021-00852-0 